\title{
Managing A Complex Case Of Acromegaly - Lessons To Learn
}

Authors: HL Yap1, E Hatfield², N Martin², R Assomull1, S Berry², A Mehta², A Falconer², N Mendoza², K Meeran², SR Mehta1.

1: Ealing Hospital, London North West Healthcare NHS Trust; 2: Charing Cross Hospital, Imperial College Healthcare NHS Trust

Patient:

Our 42-year-old patient presented with breathlessness and signs of congestive cardiac failure. Her "spade-like hands and acromegalic appearance" were noted on the post-take round. She had headaches, orthopnoea and secondary amenorrhoea. She was a poorly controlled diabetic (so oral glucose tolerance testing (OGTT) was not performed), anaemic, and previously had a thyroidectomy.

Results:

Pituitary profile at presentation showed secondary hypogonadism, normoprolactinaemia and normal free T4 indicating adequate Thyroxine replacement (Table 1).

A growth hormone day curve established levels consistently above $70 \mu \mathrm{g} / \mathrm{L}$ with elevated IGF-1 level of $65.4 \mathrm{nmol} / \mathrm{L}$.

Pituitary MRI confirmed a large $3.1 \times 2.7 \mathrm{~cm}$ pituitary macroadenoma with carotid sinus invasion and compression of the right optic nerve and chiasm.

Visual fields revealed primary inferior right hemi-field and left nasal field loss (poor reliability indices). Echocardiogram and cardiac MRI revealed significant non-ischaemic dilated cardiomyopathy, global left ventricular hypokinesis and ejection fraction of $15 \%$. BNP was $3000 \mathrm{pg} / \mathrm{ml}$ (normal range <400).
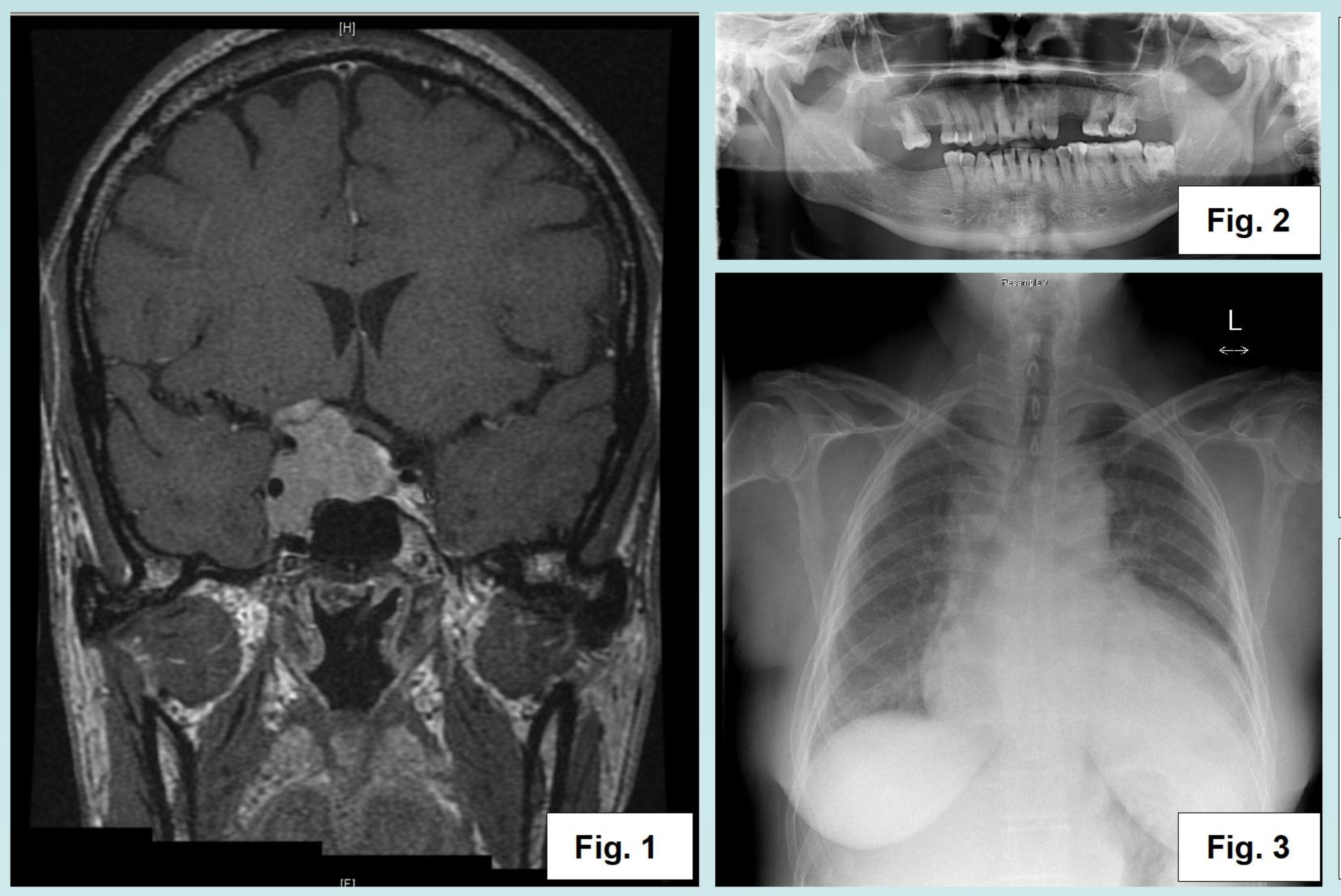

\begin{tabular}{lll} 
Table 1 & & \\
\cline { 1 - 2 } TSH & & $0.42 \mathrm{mlU} / \mathrm{L} \quad(0.27-4.2)$ \\
Free T4 & $19.5 \mathrm{pmol} / \mathrm{L}(12-22)$ \\
9am cortisol & $1140 \mathrm{nmol} / \mathrm{L}(171-536)$ \\
$\mathrm{LH}$ & $<1 \mathrm{IU} / \mathrm{L}$ \\
$\mathrm{FSH}$ & $2.5 \mathrm{IU} / \mathrm{L}$ \\
Oestradiol & $<44 \mathrm{pmol} / \mathrm{L}$ \\
Prolactin & $26 \mathrm{mlU} / \mathrm{L} \quad(102-496)$ \\
GH & $78.8 \mathrm{\mu g} / \mathrm{L} \quad(0-0.8)$ \\
IGF-1 & $65.4 \mathrm{nmol} / \mathrm{L}(12.6-35.5)$ \\
HbA1c & $11 \% / 97 \mathrm{mmol} / \mathrm{mol}$ \\
& $(4-6 \% / 20-42)$
\end{tabular}

Figure 1 Pituitary macroadenoma measuring $3.1 \times 2.7 \mathrm{~cm}$ with right carotid sinus invasion and chiasmal compression

Figure 2 Dental X-Ray showing poor dentition and interdental separation

Figure 3 Chest X-Ray with massive cardiomegaly

Monthly injections of $120 \mathrm{mg}$ Lanreotide were started, then uptitrated to once weekly with addition of $250 \mathrm{mcg}$ Cabergoline twice weekly. There was minimal biochemical and radiological response after 5 months, with growth hormone levels staying above $30 \mu \mathrm{g} / \mathrm{L}$ and IGF-1 persistently raised at 51.3 $\mathrm{nmol} / \mathrm{L}$. After radiotherapy, her tumour bulk had reduced to a size of $2.2 \times 2.6 \mathrm{~cm}$. Recent bloods show some improvement with random growth hormone level $8.3 \mu \mathrm{g} / \mathrm{L}$ and IGF-1 level $66.2 \mathrm{nmol} / \mathrm{L}$. We have applied for Pegvisomant funding.

At the pituitary MDT, a 6 month prognosis was quoted on lone medical therapy.

However, surgical debulking under general anaesthetic was high risk with estimated mortality of $>50 \%$ in patients with ejection fraction of $<30 \%$, and unlikely to be curative.

The cardiologists felt there was no role for cardiac resynchronisation therapy pre-operatively, as this would not improve her ejection fraction.

Cardiac failure optimisation and rapid uptitration of Lanreotide improved symptoms and allowed her to tolerate radiotherapy, which was the safest definitive treatment option.

If her cardiomyopathy improves, fitness for surgery will be re-evaluated.

Our case highlights challenges in diagnosing and managing acromegaly in a patient with pre-existing Type 2 diabetes and cardiomyopathy induced by a large growth hormone secreting pituitary adenoma. 